\title{
Heteromurtrella, a new tropical subgenus of Heteromurus with descriptions of two new species (Insecta: Collembola: Entomobryidae) ${ }^{1}$
}

\author{
José A. Mari Mutt ${ }^{2}$
}

\begin{abstract}
A new subgenus of Heteromurus, Heteromurtrella, is erected for the tropical members of the genus not belonging to the other tropical subgenus Alloscopus. A list is given of the 12 species placed in the new subgenus. Two new species are described: $H$. (Heteromurtrella) barrai from Gabon and $H$. (Heteromurtrella) puertoricensis from Puerto Rico. A key to the four subgenera of Heteromurus and a map detailing the holotropical distribution of the species of Heteromurtrella are presented.
\end{abstract}

\section{INTRODUCTION}

As part of a continuing revision of the subfamily Orchesellinae, the author studied members of the genus Heteromurus from throughout the world. An analysis of these specimens, from the point of view of characters recently introduced in the field of collembolan taxonomy, made it imperative that a new subgenus, Heteromurtrella, be erected for the tropical members (fig. 17) of the genus not belonging to the other tropical subgenus Alloscopus (reviewed by Mari Mutt (7).

The following species are herein placed in the new subgenus Heteromurtrella: Heteromurus abruptus (Salmon) 1951 (8), H. diommatus Denis 1931 (5), H. dubius Delamare Deboutteville and Paulian 1951 (4), $H$. lividus (Salmon) 1954 (9), H. mirificus (Salmon) 1954 (9), H. nitens Yosii 1964 (11), H. schoetti Denis 1931 (5), H. similis Barra 1968 (2), H. stannardi Mari Mutt 1977 (6), H. subdubius Barra 1968 (2). Material for study has been available for all species save $H$. nitens, but for this one the original description is adequate enough to permit the inclusion of the species in the new subgenus. Two new species $(H$. barrai from Gabon and $H$. puertoricensis from Puerto Rico) are described below making a total of 12 species in the subgenus Heteromurtrella.

\section{RESULTS}

\section{Genus Heteromurus Wankel 1860 (10)}

\section{Subgenus Heteromurtrella NEW}

Habitus typical (e.g. fig. 5, see also Mari Mutt (6), p. 328, fig. 4). Length of adults (excluding antennae and furcula) from about $0.7 \mathrm{~mm}$ (i.e. $\mathrm{H}$.

' Manuscript submitted to Editorial Board July 18, 1978.

${ }^{2}$ Department of Biology, University of Puerto Rico, Mayagüez, P. R.

This contribution is based in part on a thesis deposited by the author in the Department of Entomology of the University of Illinois at Urbana-Champaign in partial fulfillment of the requirements for the degree of Doctor of Philosophy, 1978. 
abruptus) to about $2.0 \mathrm{~mm}$ (e.g. H. schoetti) depending on species. Pigment absent, restricted to eye patch, restricted to anterior portion of head and to antennae, or specimens pigmented throughout. Color pattern slightly variable intraspecifically. Pigment, when present in preserved specimens, dark-blue with exception of light orange pigment of $H$. puertoricensis. Head, body, Ants. 1-3 and venter of furcula clothed with strongly striated, apically rounded or truncated, light to dark brown scales. Tibiotarsi of some species devoid of scales, other segments scaled.

Antennae five-segmented due to subdivision of Ant. 1. Ant. 5 annulated. Antennae about half as long as length of head and body combined. Pin seta of apex of Ant. 5 found only in $H$. subdubius. Head macrochaetotaxy constant intraspecifically, similar to that shown in figures 1 and $2, \mathrm{~S}_{0}$ always present, posterior portion of head with at least one (frequently with three) macrochaetae (e.g. fig. 1 letter P).

Postantennal organ absent. Eyes $6+6$ (H. abruptus), $2+2,1+1$ or absent depending on species. Periocellar pigmentation intraspecifically present or absent. Prelabral setae four, smooth, not bifurcated, subequal in length. Labral chaetotaxy with formula 5,5,4; all setae smooth. Labral papillae present, of type II (all four papillae conelike, e.g. fig. 12) or III (only inner pair conelike, e.g. fig. 11). Type of labral papilla constant intraspecifically. Chaetotaxy of labial triangle similar for all species (e.g. fig. 9, see also Barra (2), p. 117, fig. 1); posterior row with smooth and ciliated setae, without scales. Relative lengths of setae of maxillary palp (fig. 13) and differentiated seta of outer labial papilla (fig. 15) similar in almost all species. Venter of head with smooth and ciliated setae but setae of quadrangle seen immediately behind labial triangle, along median cleft, are smooth (fig. 8).

Tibiotarsi only with clearly ciliated setae except in $H$. dubius where an inner row of smooth (finely ciliated) setae is found. Smooth tibiotarsal

Plate I. Figs. 1-4. Fig. 1. Heteromurus (Heteromurtrella) puertoricensis-Head macrochaetotaxy, each dot represents a seta. $\mathrm{M}=$ median, $\mathrm{S}=$ sutural, $\mathrm{P}=$ posterior. $2 . H$. (Heteromurtrella) barrai-Head macrochaetotaxy. 3. H. (H.) puertoricensis-Coxal macrochaetotaxy of pro-(a), meso- (b), and metathoracic (c) legs. 4. H. (H.) puertoricensisMucro.

Plate II. Figs. 5-9. Fig. 5. H. (H.) puertoricensis-Habitus. 6. H. (H.) puertoricensisBody macrochaetotaxy. 7. H. (H.) barrai-Body macrochaetotaxy. 8. H. (H.) puertoricensis-Rectangle of setae immediately behind labial triangle along median cleft. 9. $H$. $(H$.) puertoricensis-Chaetotaxy of labial triangle.

Plate III. Figs. 10-16. Fig. 10. H. (H.) puertoricensis-Metathoracic claws. 11. H. $(H$. puertoricensis-Labral papillae. 12. H. (H.) barrai-Labral papillae. 13. H. (H.) puertoricensis-Maxillary palp. 14. H. (H.) puertoricensis-Apex of Ant. 5 with distally knobbed seta. 15. $H$. (H.) puertoricensis-Outer labial papilla and its differentiated seta. $16 . H$. $(H$.) puertoricensis - Lateral view of manubrium and proximal portion of dens showing arrangement of one of the two longitudinal rows of smooth setae.

Plate IV. Fig. 17. Geographic distribution of the species of the subgenus Heteromurtrella. 

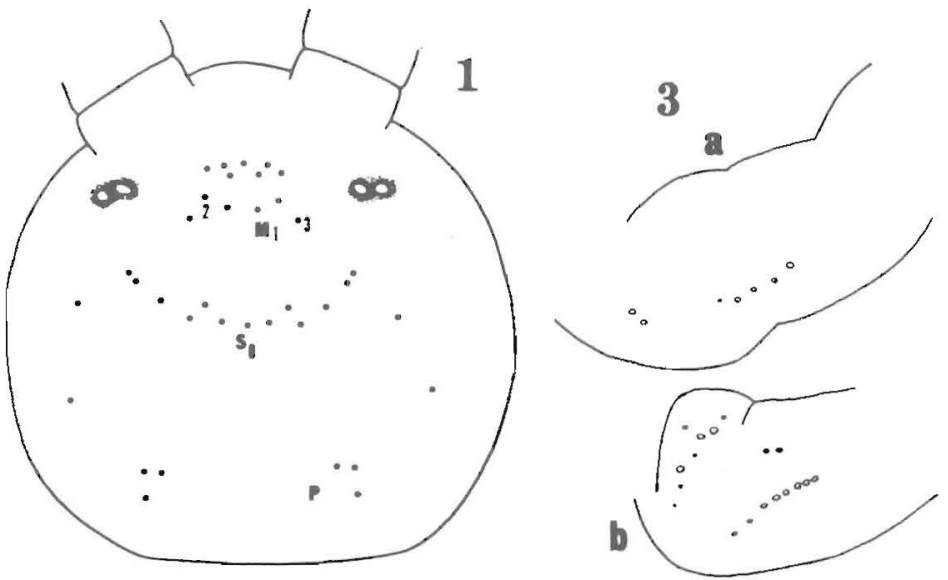

2
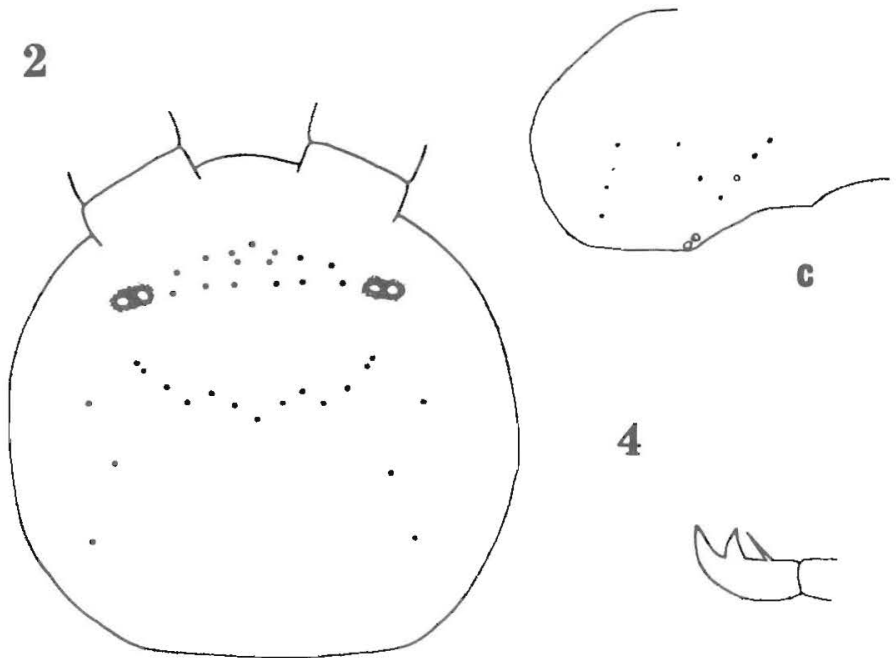

Plate I

setae analogous to those found forming rows in species of Heteromurus s. str. (e.g. H. nitidus) and in H. (Alloscopus) tetracanthus are absent. A single smooth seta opposite the tenent hair of metathoracic legs (c.f. fig. 10) present in all species of subfamily. Ungues bi-, tri-, or quadridentate; all types may be present within a species. Unguiculus with an outer tooth which in most species is fairly large; some species also with a tooth basally along inner lamella. Tenent hair apically lanceolate.

Body macrochaetotaxy similar to patterns shown in figures 6 \& 7 . Abd. 1 with at least one macrochaeta per side, most species with three setae per side. Manubrial organ absent. Dorsum of manubrium with two parallel longitudinal rows of conspicuous smooth erect setae. One pair of 

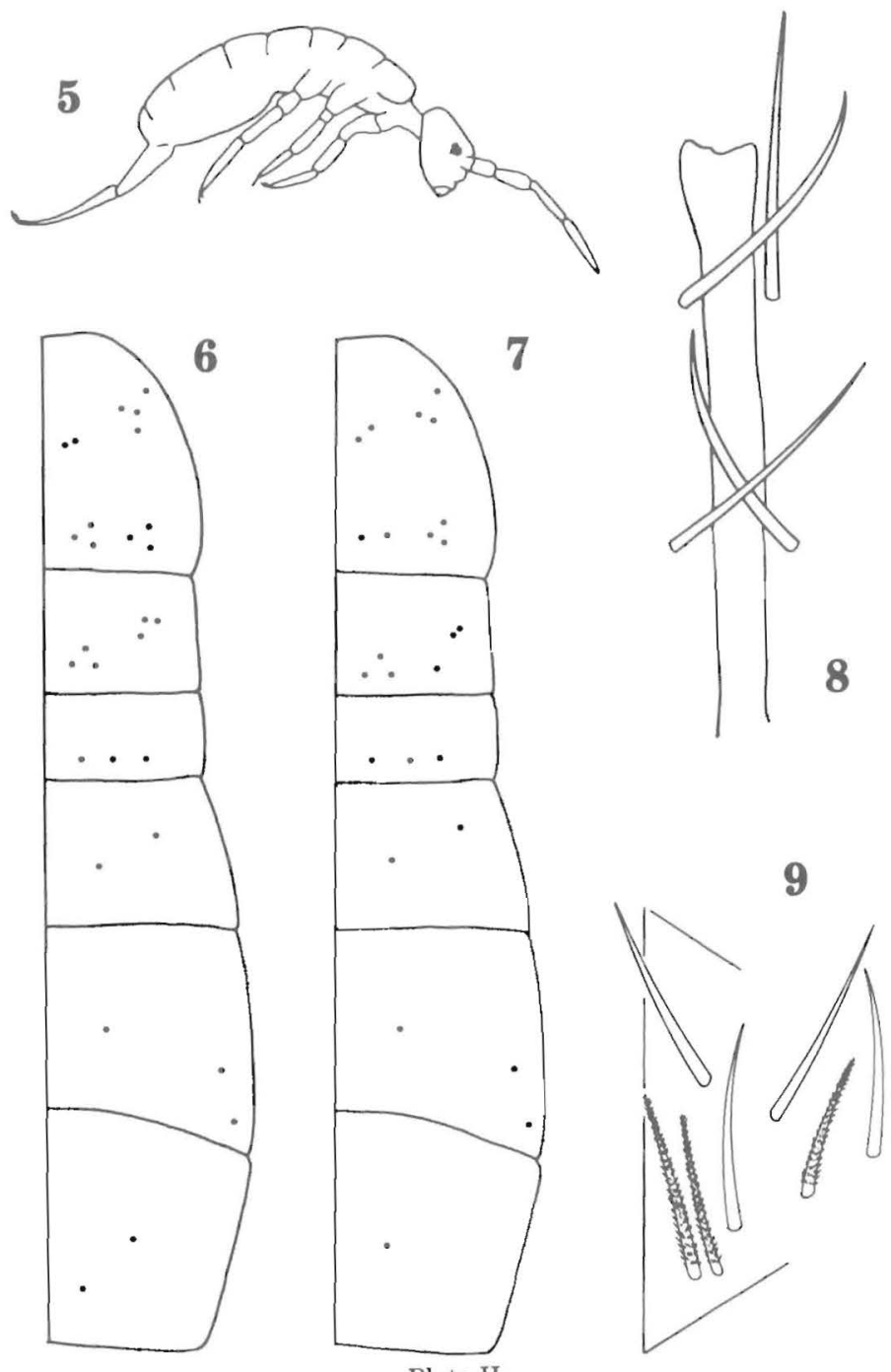

Plate II

these setae inserted proximally on dorsal portion of dentes. Dental spines absent. Mucro interspecifically with or without basal spine.

Type Species

Heteromurus (Heteromurtrella) puertoricensis n. sp., by present designation.

\section{Diagnosis}

The new subgenus may be recognized by means of the following key: 

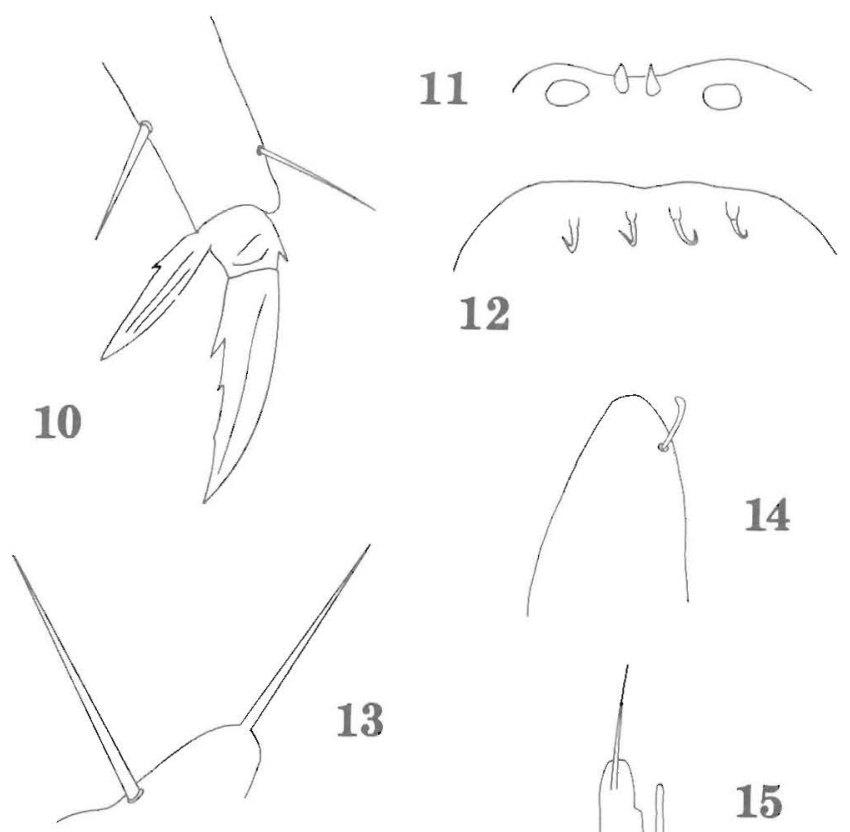

\section{2}
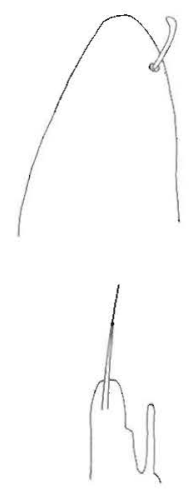

15

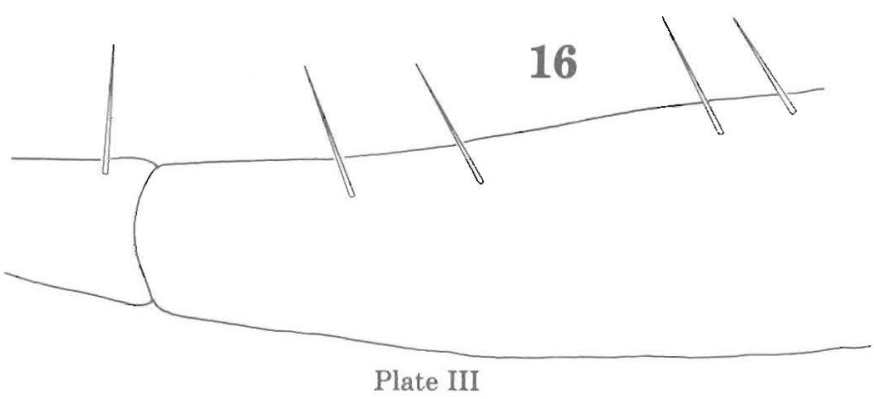

KEY TO THE SUBGENERA OF HETEROMURUS WANKEL

1. Ants. 4 \& 5 conspicuously annulated (see Absolon (1), p. 430, fig. 2); caves in Spain and Yugoslavia ...... Verhoeffiella Absolon 1900 (1) Only Ant. 5 annulated.

2. Abd. 1 of adults without macrochaetae; $\mathrm{S}_{0}$ (fig. 1 ) absent; adults almost always over $2.3 \mathrm{~mm}$ long; holarctic except for six isolated records of two species in the tropics and one of those species from New Zealand Heteromurus s. str. Abd. 1 of adults with at least one (most species with three) macrochaetae; $\mathrm{S}_{0}$ (fig. 1) present; adults almost never over $2.1 \mathrm{~mm}$ long; tropical 


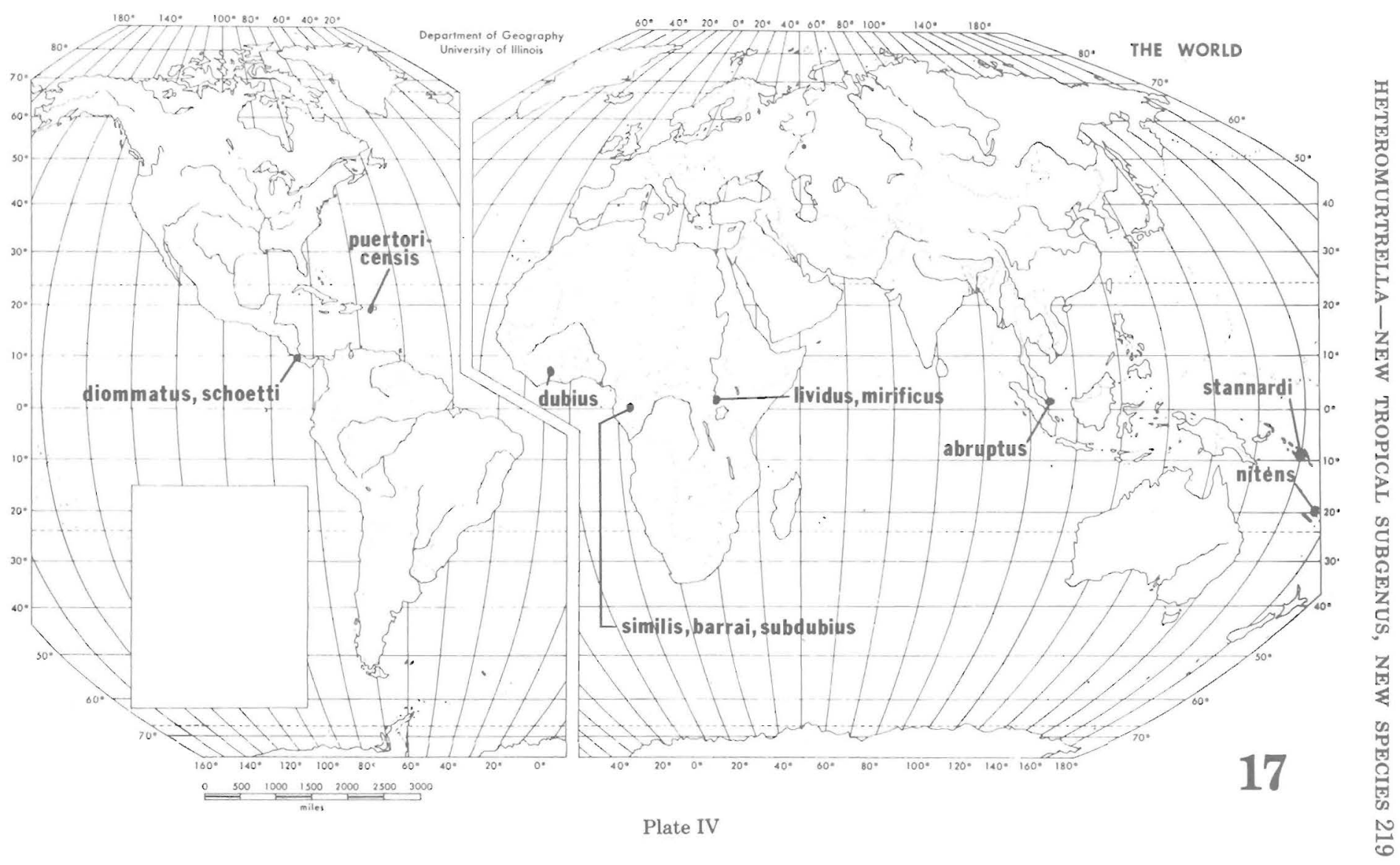


3. Dental spines present; posterior margin of head without macrochaetae (see Mari Mutt (7), p. 244, figs. 1 \& 2); South East Asia

Alloscopus Börner 1900 (3)

Dental spines absent; posterior margin of head with at least one (most species with three) macrochaetae; holotropical (fig. 17) Heteromurtrella NEW

Heteromurus (Heteromurtrella) puertoricensis n. sp.

Habitus as in figure 5. Length ranging from 0.72-1.3 mm. Live specimens light orange with dark eye patch; after prolonged preservation most orange pigment seems to fade. Apex of Ant. 5 with a conspicuous distally knobbed seta (fig. 14). Eyes $2+2$. Head macrochaetotaxy as in figure 1 , seta $\mathbf{M}_{3}$ about three fifths length of $\mathrm{M}_{1}$ or $\mathrm{M}_{2}$. Labral papillae of type III (fig. 11); lateral pair flaplike, median pair conelike. Labial chaetotaxy (fig. 9) typical of subgenus. Setae of maxillary palp as in figure 13. Differentiated seta of outer labial papilla not reaching apex of its papilla (fig. 15). Setae forming quadrangle immediately behind labial triangle, along median cleft (fig. 8), smooth; other setae of venter of head also smooth. Coxal macrochaetotaxy as in figure 3. Tibiotarsi without smooth setae or scales. Structure of claws as in figure 10; ungues tri-, or quadridentate, no bidentate ungues found. Unguiculus without teeth along inner lamellae. Body macrochaetotaxy as in figure 6, pattern constant regardless of size of specimen. Dorsum of manubrium with four pairs of conspicuous erect smooth setae arranged in two groups near proximal and distal ends (fig. 16); proximal portion of dentes with a pair of these setae. Mucro (fig. 4) with basal spine.

\section{Diagnosis}

The species is most similar to $H$. (Heteromurtrella) subdubius and $H$. (Heteromurtrella) dubius. From the first it may be distinguished by the type of labral papillae (II in subdubius, III in puertoricensis), mucro with basal spine in the new species, and periocellar pigmentation absent in subdubius. From dubius it may be separated by the absence of smooth setae on the tibiotarsi of puertoricensis and by the relative lengths of the differentiated seta of the outer labial papilla (differentiated seta reaches apex of its papilla in dubius, falls short in puertoricensis, see fig. 15).

\section{Comments}

The intraspecific variability of several characters was investigated for 36 paratypes from the type locality. Results are as follows: A) The size of the inner pair of ungual teeth is variable, at times these teeth are quite large (winglike); B) ungues may be tri-, or quadridentate; both types 
sometimes found in same specimen; C) the outer unguicular tooth is variable in position along its lamella; D) Abd. 4 generally has two macrochaetae (fig. 6); near the base of the hindmost one may find in large specimens a seta whose socket is very much like that of a regular macrochaeta but this seta is shorter than a regular macrochaeta.

\section{Material Examined and Repository}

The Illinois Natural History Survey, Urbana, Illinois, has the following material: Puerto Rico, Maricao, Rd. 120, km. 13.9, near stone tower, January 6, 1977, leaf litter, J. A. Mari Mutt, col. Holotype and 37 paratypes. Maricao, Rd. 120, km. 13.6, in the vacational center, January 5, 1977, leaf litter, J. A. Mari Mutt, col. Seven paratypes. Maricao state forest, near stone watch tower, January 24, 1960, forest debris, G. E. Haas, col. Two paratypes. Mayagüez, Rd. 349, km. 5.9, December 13, 1976, leaf litter, J. A. Mari Mutt, col. Two paratypes. The British Museum (Natural History), London, has five paratypes from the type locality. The author has in his collection five paratypes from the type locality and two from each of the other localities.

\section{Heteromurus (Heteromurtrella) barrai n. sp.}

Heteromurus mirificus (Salmon) sensu Barra (2), p. 114, nec. Salmon (9).

Habitus typical of subgenus. Largest specimen at hand $1.0 \mathrm{~mm}$. Pigment restricted to eye patch. Ant. 5 apically with distally knobbed seta. Eyes $2+2$ surrounded by dark pigment. Head macrochaetotaxy as in figure 2. Labral papillae of type II (fig. 12), all papillae very long, apically hooked upwards. Tibiotarsi without smooth setae or scales. Ungues bi-, or tridentate. Inner basal margin of unguiculus with toothlike projection. Body macrochaetotaxy as in figure 7. Manubrium with a single pair of smooth erect setae placed upon basal dorsal portion (from Barra (2), not seen). Dentes without smooth setae. Mucro with basal spine.

\section{Diagnosis}

The species is closest to the other African members of the subgenus from which it may be readily separated by its head and body macrochaetotaxy. Curiously, the former pattern is like that of $H$. similis and mirificus while the latter is like that of $H$. dubius and subdubius.

\section{Comments}

I studied three paratypes of $H$. mirificus (Salmon) (one is in the British Museum (Natural History), London and two are in the Museum of Comparative Zoology, Harvard University, Cambridge, Massachusetts) and it is clear that H. mirificus sensu Salmon 1954 and mirificus sensu 
Barra 1968 are different species. The latter I have named barrai after Dr. J. A. Barra whose 1968 (2) contribution to the taxonomy of the genus is of much importance.

Barra (2) presented figures of the head and body macrochaetotaxy, collophore chaetotaxy, claw structure and manubrium of the species here called $H$. barrai.

\section{Material Examined and Repository}

The collection of Dr. J. A. Barra (Laboratoire de Zoologie et d'Embryologie expérimentale, Université Louis Pasteur, 67000 Strasbourg, France) has the following material: Gabon, Ipassa plateau, IPA g 6, J. A. Barra, col. Holotype and two paratypes. As preceeding but IPA e 17, one paratype. As preceeding but e 7, one paratype.

\section{RESUMEN}

Se describe un nuevo subgénero de Heteromurus, Heteromurtrella, para las especies tropicales del género no pertenecientes a Alloscopus, el otro subgénero tropical. Se presenta una lista de las 12 especies colocadas en Heteromurtrella. Se describen dos nuevas especies: H. (Heteromurtrella) barrai de Gabon y H. (Heteromurtrella) puertoricensis de Puerto Rico. Incluidas estan además, una clave para los cuatro subgéneros de Heteromurus y un mapa que detalla la distribución geográfica de las especies de Heteromurtrella.

\section{LITERATURE CITED}

1. Absolon, K., 1900. Über zwei neue Collembolen aus den höhlen des österreichischen occupationsgebietes, Zool. Anz., 23(261): 427-431.

2. Barra, J. A., 1968. Contribution a l'étude du genre Heteromurus Wankel 1860 (Collemboles), Biol. Gabon., 4: 105-117.

3. Börner, C., 1906. Das system der Collembolen nebst beschreibung neuer Collembolen des Hamburger Naturhistorischen Museums, Mitt. Naturhist. Mus. Hamburg, 23: 147-188.

4. Delamare Deboutteville, C. \& Paulian, R., 1952. Faune des nids et des terriers en Basse Côte d'Ivoire, Encycl. Biogeogr. Ecol. VII, Paul LeChevalier, ed, 12, rue de Tournon, Paris $\left(\mathrm{VI}^{\mathrm{e}}\right), 116 \mathrm{pp}$.

5. Denis, J. R., 1931. Contributo alla conoscenza del "microgenton" di Costa Rica III. Collemboles de Costa Rica avec une contribution aux espèces de l'ordre (deuxième note), Boll. R. Lab. Ent. Agr. Portici, 27: 222-322.

6. Mari Mutt, J. A., 1977. A new species of Heteromurus from the Solomon Islands (Collembola: Entomobryidae). Pan-Pac. Entomol., 52(4): 326-330.

7. - 1978. The taxonomic status of Alloscopus and redescriptions of its two species (Collembola: Entomobryidae), Pan-Pac. Entomol., 53(4): 241-249.

8. Salmon, J. T., 1951. Some Collembola from Malaya, Proc. Roy. Ent. Soc. London, Ser. B, 20(11/12): 131-141.

9. - 1954. Orchesellini (Collembola) from East Africa, Ann. Mag. Nat. Hist., Ser. 12, 7: 122-127.

10. Wankel, H., 1860. Beitráge zur fauna der mäharischen höhlen, Lotos (Prague), 10: 201206.

11. Yosii, R., 1964. Some Collembola of the Tonga Islands. Kontyû, 32(1): 9-17. 